\title{
Estudo comparativo de técnicas computacionais para classificação de emoções
}

\author{
Sara L. de Melo ${ }^{1}$, Fábio F. de Moura ${ }^{2}$, Kely Macedo ${ }^{1}$, Fabiano S. R. Alves ${ }^{1}$, \\ Márcia A. Fernandes ${ }^{1}$ \\ ${ }^{1}$ Departamento de Ciência da Computação \\ Universidade Federal de Uberlândia \\ Uberlândia - Minas Gerais - Brasil \\ ${ }^{2}$ Departamento de Engenharia e Computação \\ Instituto Federal de Minas Gerais \\ Bambuí - Minas Gerais - Brasil \\ email\{saraluziademelo,fabioferreirademoura,kelymadias0,fabiano.fsra\}@gmail.com, marcia@ufu.br
}

\begin{abstract}
This article presents a comparative study of computer techniques to automatic detect the six basic emotions (happiness,sadness, anger, disgusting,fear and surprise). For this, it was valued the database of Cohn-Kanade, which has grounding in FACS theory, containing real attributes of several students from different ethnicities and ages. After that, every set of facial expressions was associated to a determined emotion. For validation it was created a database and to classify they were used three computer techniques - Neural Networks type MLP, Neural networks with Activation Functions (RBF) and Bayesian Networks. The results obtained by the three technics were compared and it was identified high rate precision for Bayesian Networks.
\end{abstract}

Resumo. Este artigo apresenta um estudo comparativo de técnicas computacionais para detecção automática de seis emoções básicas (alegria, tristeza, raiva, desgosto, medo e surpresa). Para isto, foi avaliada a base de dados de Cohn-Kanade, cuja fundamentação se encontra na teoria FACS, contendo atributos reais de vários estudantes de diferentes etnias e idades. Posteriormente, associou-se cada conjunto de expressões faciais a determinada emoção. Para validação foi criada uma base de dados e para classificação foram utilizadas três técnicas computacionais - Redes Neurais do tipo MLP, Redes Neurais com Funções de Ativação (RBF) e Redes Bayesianas. Os resultados obtidos pelas três técnicas foram comparados e identificou-se alta taxa de precisão para as redes Bayesianas.

\section{Introdução}

Sistemas computacionais que extraem características particulares de indivíduos tem sido bastante difundidos na área da computação. Desse modo, é possível averiguar como essas características específicas de cada indivíduo podem ajudá-lo em situações corriqueiras. No ambiente educacional pode-se, por exemplo, usá-las para promover adaptatividade no oferecimento de material de estudo ao estudante.

Darwin foi um dos primeiros naturalistas a estudar reconhecimento facial com seres humanos para mostrar a importância das expressões mostradas na face dos indivíduos 
como fator social. Essas ideias de Darwin fez com que fossem desenvolvidas teorias sobre o reconhecimento de padrões com finalidade de auxiliar o ser humano em suas atividades [Garcia 2009].

Com base neste contexto, [Ekman and Friesen 1978] iniciaram seus estudos a partir de ideias Darwinistas, onde notaram que existem emoções universais entre grupos sociais distintos expressas pelo ser humano. Métodos cognitivos de ensino tem sido utilizados, aprimorados e aplicados em sistemas educacionais para extração de características. Fatores emocionais identificados em estudantes durante o processo de aprendizado podem ser utilizados favoravelmente no processo de construção do aprendizado.

Emoções podem ser uma chave para proporcionar ao estudante melhores formas de metodologias de ensino. Nessa perspectiva a computação afetiva pode aprimorar este processo entre o estudante e o aprendizado. Num curso voltado a computador, onde um estudante, com o auxílio de uma webcam, a qual captura expressões faciais do estudante mapeando as emoções dele é possível inferir como será um melhor método de ensino aplicado a ele.

Neste trabalho foi realizado um estudo comparativo entre três técnicas computacionais usadas para classificação de padrões aliado à teoria de Facial Action Coding System (FACS) [Ekman and Friesen 1978, Ekman et al. 2002]. Esta teoria descreve todos os possíveis movimentos faciais visíveis denominados de Unidades de Ação (UA's) do indivíduo, cada UA está relacionada com a contração de seus músculos, e também a cada movimento da face. Com a análise das técnicas escolhidas pretende-se verificar qual a mais adequada na classificação de emoções de um estudante durante seu processo de estudo e, futuramente, poder incorporá-lo a um Sistema Adaptativo (SA), onde baseado nos seus fatores cognitivo-emocionais ofereça o melhor Objetos de Aprendizagem (OA).

Assim, primeiramente faz-se necessário uma análise de um Banco de Dados (BD) de imagens reais. Para este trabalho foi escolhido o BD desenvolvido por [Kanade and Cohn 2005], pois possui informações de pessoas de várias etnias, sexo e idade. Além disso, nesse BD contém um conjunto de UA's. Com base neste conjunto, a etapa de mineração de dados consistiu em relacionar cada agrupamento de UA's a cada uma das seis emoções. Logo após foram utilizados três métodos computacionais para analisar partir dele, como cada técnica faria a classificação dessas emoções. Utilizou a ferramenta [Weka 2014] para classificação das emoções. Foram executados testes e análise de resultados com três técnicas computacionais, sendo elas, Redes Neurais Artificiais (RNA) do tipo Multi-Layer Perceptron (MLP) utilizando o algoritmo de treinamento Backpropagation; Rede Basis Functions Networks (RBFN) - Funções de Base Radial (RBF) - e Redes Bayesianas (RB). Os Resultados enfatizam que tais técnicas têm bom resultado para a classificação do perfil emotivo do estudante para este problema.

Este artigo está organizado da seguinte maneira: na Sessão 2 mostra um estudo sobre as Emoções e Computação Afetiva; na Sessão 3 é apresentada a teoria FACS e EMFACS; na Sessão 4 são descritas as técnicas computacionais utilizadas e também o desenvolvimento do trabalho; são apresentados os resultados e discussões na Sessão 5 e, na Sessão 6 são apresentadas as considerações finais. 


\section{Emoções e Computação Afetiva}

A utilização do termo "emoção" acontece, muitas vezes, de forma desmedida, mas, conceitualmente, emoção é considerada como um elemento do conjunto genérico de estados afetivos. Ao contrário, por exemplo, do humor que costuma ter uma duração mais longa e não tem uma causa bem definida, já emoção é breve e ocorre em razão de um estímulo. Nesse contexto, uma expressão emocional corresponde àquilo que é demonstrado a outras pessoas, voluntária ou involuntariamente [Oliveira and Jaques 2013].

Emoções são expressões humanas que são exibidas de forma visual através de meios fisiológicos. Essas evidências aparecem de forma clara num indivíduo, quando este é colocado em determinadas situações, denominando assim as suas habilidades emocionais que fazem parte do que pode ser chamado de "inteligência emocional".

Uma das maneiras mais importantes para os seres humanos exibir emoções é através de expressões faciais [Azcarate et al. 2005]. Desse modo numa interação humanocomputador, pensando-se em sistemas que capturem a emoção de um estudante, para que torne o processo de ensino mais eficaz, pode vir a ser a captura do reconhecimento do estado emocional do ser humano a partir de sua face, o qual pode revelar-se uma inestimável ferramenta.

[Azcarate et al. 2005] em seu trabalho descreve em tempo real um sistema de reconhecimento de expressões faciais automático usando vídeo ou webcam como entrada, sendo que desde o início da década de 1970 estudos relacionados ao reconhecimento de emoções humanas através de expressões faciais vem se tornando trivial no meio científico [Ekman and Rosenberg 2005, Azcarate et al. 2005].

[Ekman and Rosenberg 2005] encontrou evidências para apoiar a universalidade em expressões faciais, sendo que estas "expressões faciais universais" são aqueles que representam as seis principais emoções expressas pelos seres humanos: felicidade, tristeza, raiva, medo, surpresa e desgosto.

Eles estudaram expressões em muitas culturas, de modos diferentes, mas foram encontradas muitas semelhanças nas expressões e no reconhecimento de emoções na face [Azcarate et al. 2005]. [Ekman and Rosenberg 2005] desenvolveu um sistema de codificação de expressões faciais onde os movimentos da face são descritos por um conjunto de Unidades de Ação (UA’s), sendo que através de cada UA algumas emoções estão relacionadas à base muscular da face.

A Computação Afetiva leva em consideração as emoções dos seres humanos para a confecção de hardwares e de softwares para serem usados com finalidades diversas. Muitas áreas do conhecimento, tais como a Inteligência Artificial, estão envolvidas nos estudos e pesquisas da computação afetiva. Seu objetivo é inferir um "diálogo" entre um indivíduo e a máquina, baseando-se em seu estado emocional, criando, com isso, situações "inteligentes" que possam inferir soluções (dependendo da aplicação) a partir do "estados emocional" do indivíduo.

Neste sentido, tenta-se fazer com que a emoção, existente na comunicação entre pessoas, esteja presente também durante a interação entre homem e computador. $\mathrm{O}$ computador deve entender as emoções humanas e/ou expressar afeto em determinado momento, para que a máquina possa ter a capacidade de percepção dos estados emocionais 
do seu usuário e adaptar seu comportamento funcional [Diniz et al. 2013].

[Silva 2012] propôs um sistema que classifica sete diferentes expressões: felicidade, raiva, tristeza, surpresa, desgosto, medo e neutra utilizando abordagens baseadas em correspondência entre modelos e RNA. As duas bases de dados utilizadas nesse trabalho as imagens apresentam planos uniformes ou não e os indivíduos apresentam barba, bigode e óculos. Os resultados experimentais obtidos por [Silva 2012] tiveram taxa média de acerto de $97,62 \%$ para as sete diferentes expressões faciais definidas.

\section{Teoria FACS - EMFACS e Unidades de Ação}

A teoria Facial Action Coding System (FACS) criada por Ekman e Friesen [Ekman and Friesen 1978, Ekman et al. 2002, Ekman and Rosenberg 2005] é um sistema abrangente, com base anatômica e menos sobrecarregado por noções teóricas sobre o que a face deve fazer do que os outros sistemas existentes. Ele descreve todos os possíveis movimentos faciais distintos visíveis baseado em quarenta e quatro Unidades de Ação (UA's). Cada UA tem seu código numérico e seus respectivos músculos que são contraídos para cada movimento da face, onde cada UA foi cuidadosamente estudada, sendo que cada músculo representa uma ação facial que é mapeada através das UA's enumeradas de 1 a 44 (Exemplo: UA1 significa o levantamento da sobrancelha interna), sendo que a tabela com a associação completa dessas UA's pode ser vista no trabalho de [Ekman and Friesen 1978].

Os eventos faciais codificados pelo FACS podem ser classificados em categorias emocionais e não-emocionais. O EMotion FACS (EMFACS) foi então criado para classificar os movimentos faciais em expressões faciais da emoção baseado nas UA's do FACS [Ekman and Friesen 1978, Ekman et al. 2002, Ekman and Rosenberg 2005].

Tem-se na Figura 1 um exemplo de expressões frontais vistas a partir do banco de dados utilizado neste trabalho [Kanade and Cohn 2005]. Cada seqüência começa com uma expressão neutra e procede a uma expressão alvo. No exemplo da Figura 1 a expressão alvo é a surpresa.

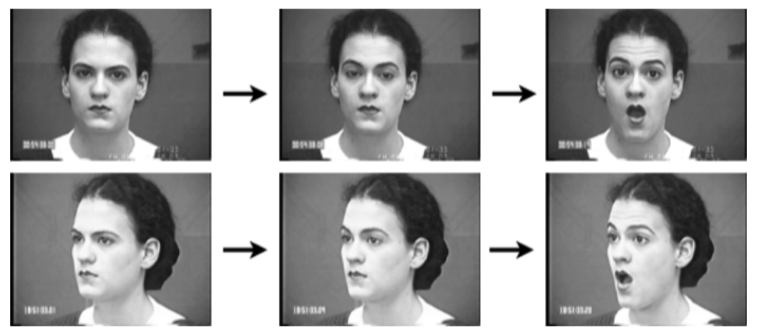

Figura 1. Emoção surpresa classificada por [Kanade and Cohn 2005] com as combinações das UA's $1+2+5+27$.

EMFACS é um método objetivo que usa o FACS para responder somente as ações faciais relevantes para detectar uma emoção, ele porém, tem um número menor de combinações das UA's e possui uma versão modificada de regras e procedimentos de medição, intencionalmente feito para diminuir o tempo de resposta quando o interesse é somente em classificar as emoções da face.

No trabalho de [Azcarate et al. 2005] é utilizado um conjunto de UA's utilizadas 
que descrevem pontos da face, bem como as expressões que revelam, sendo que tais UA's são as características que podem ser usadas como classificadores de emoções.

Foram determinados, no sistema FACS, os músculos que podem ser controlados voluntariamente e de forma independente, e como eles alteram a aparência da face. Tais mudanças foram mapeadas, dando origem às UA's que compõem as expressões faciais. Cada UA apresenta o conjunto de músculos que devem ser relaxados ou contraídos para resultar em um pequeno movimento em uma parte do rosto. Nesse sistema foram definidas 44 UA's

Os eventos faciais codificados pelo FACS podem ser classificados em categorias emocionais e não-emocionais. O EMFACS (EM= emotion, FACS) foi então criado para classificar os movimentos faciais em expressões faciais da emoção baseado nas UA's do FACS [Ekman and Friesen 1978, Ekman et al. 2002, Ekman and Rosenberg 2005]. EMFACS é um método objetivo que usa o FACS para responder somente as ações faciais relevantes para detectar uma emoção, no entanto ele possui um número menor de combinações de UA's, além de possuir uma versão modificada de regras e procedimentos de medição, provindas intencionalmente para diminuir o tempo de resposta quando o interesse é somente em classificar as emoções da face.

No presente trabalho foi utilizado os fundamentos do FACS para identificar as expressões faciais e o EMFACS para identificar através desse conjunto de expressões, as emoções correspondentes. Para tanto foi utilizado o banco de dados de [Kanade and Cohn 2005] AU-Coded Facial Expression Database que possui uma diversidade coleta de expressões faciais.

\section{Trabalho Realizado e Técnicas Utilizadas}

Através da computação afetiva amparada pelas técnicas da inteligência artificial, temse como proposta a detecção automática das emoções de indivíduos. Acredita-se que ao incorporar tais informações em um ambiente virtual de aprendizagem (AVA) o próprio sistema seja capaz de estimular cada estudante que encontra-se em uma emoção que possa interferir no aprendizado. E, posteriormente, ofereça ao estudante Objeto de Aprendizagem (OA) diferenciados utilizando Estilos de Aprendizagem como no trabalho proposto por [Moura et al. 2013].

Para o processo de classificação das seis emoções básicas proposta, primeiramente efetuou-se uma análise ao Banco de Dados (BD) Cohn-Kanade Database FACS proposto por [Kanade and Cohn 2005], que é baseado na teoria FACS proposta por [Ekman and Friesen 1978].

Esse BD é composto por agrupamentos de UA's que foram expressas por 97 estudantes, com idades entre 18 a 30 anos. Além disso, há diversidade em sexo e etnias, sendo $65 \%$ compõem expressões de estudantes do sexo feminino e $35 \%$ do sexo masculino. Quanto a etnia, $15 \%$ dos testes foram realizados com afro-americanos, $3 \%$ latinos ou asiáticos e o restante eram de etnia americana.

A teoria FACS especifica-se às ações dos músculos sem associá-las a uma determinada emoção. Nesse intuito, foi realizada uma análise de todos os atributos da base de dados supracitada, para que, em seguida, efetuasse a associação de cada conjunto de UA's às emoções. Compreendeu-se um total de 379 conjuntos de expressões faciais. Esta 
análise foi executada observando vídeos [Kanade and Cohn 2005] de cada entrevistado juntamente com uma análise precisa do agrupamento de músculos de acordo com a teoria EMFACS.

Após essa etapa observou-se que na base de dados, apesar da diversidade de idade, sexo e etnias existem UA's isoladas ou em grupos que inferem em uma emoção específica. A Tabela 1 exibe as seis emoções e seus respectivos músculos - sempre observados no estudo - que foram contraídos na maioria dos estudantes ao expressar estas emoções.

Tabela 1. UA's comuns para classificação de emoções [Lucey et al. 2010]

\begin{tabular}{|l|l|}
\hline Emoção & UA Contraída \\
\hline Raiva & Devem ocorrer as UA 23 e UA 24 \\
\hline Desgosto & UA 9 ou UA 10 deve estar presente \\
\hline Medo & Deve ocorrer a combinação das UA 1 + UA 2 + UA 4. Contendo ou não a UA 5 \\
\hline Alegria & UA 12 deve estar presente \\
\hline Tristeza & UA 1 + UA 4 + UA 15 devem estar presentes. Uma exceção é UA 6 + UA 15 \\
\hline Surpresa & UA 1 + UA 2 devem estar combinadas. \\
\hline
\end{tabular}

Apesar dessas UA's em comum a cada emoção foi observado que o conjunto delas difere para cada indivíduo, sendo que para cada um podem ser contraídas cinco, ou mais, UA's ao expressar a emoção alegria, por exemplo. Em contrapartida outra pessoa contrai apenas a UA 12 que esteve presente em todos os conjuntos de UA's que infere a emoção alegria nessa base de dados de [Kanade and Cohn 2005].

Após a associação de agrupamentos de UA's a determinada emoção foi desenvolvida uma base de dados para treinamento com a finalidade de classificação automática das seis diferentes emoções através de três técnicas computacionais escolhidas para o estudo em questão. Assim, na base de dados foi desenvolvida um total de 379 instâncias, sendo elas divididas em 101 instâncias atribuídas à emoção alegria, 72 à emoção tristeza, 45 à emoção desgosto, 77 à emoção surpresa, 36 à emoção raiva e, por fim, 48 instâncias à emoção medo.

Para a classificação dos dados usou-se as técnicas de Rede Neural Artificial do tipo MPL, Rede Neural com função de ativação de Base e Redes Bayseanas. A validação e os testes foram realizados com o auxílio da ferramenta [Weka 2014].

\subsection{Classificação de Emoções utilizando Redes Neurais Artificiais tipo $M L P$}

Numa RNA MLP, basicamente, existem três camadas (entrada, intermediária e saída), sendo que na camada intermediária podem existir outras camadas, dependendo da demanda do problema a ser solucionado/otimizado.

Neste trabalho, a classificação das emoções básicas é realizada com esse tipo de rede neural utilizando o algoritmo de aprendizado backpropagation [Fausett 1994]. A estrutura da RNA possui 7 neurônios na camada de entrada correspondente a combinação de UA's expressas na base de dados. Possui, também, uma camada oculta com 6 neurônios e ainda, uma camada de saída contendo 6 neurônios (emoções básicas). Foram executados testes com a base de dados desenvolvida para essa técnica computacional, os resultados da classificação das emoções utilizando esse modelo de RNA são mostrados na matriz de confusão na Tabela 2. 


Tabela 2. Matriz de Confusão utilizando a técnica RNA - MLP.
\begin{tabular}{|l|l|l|l|l|l|l|}
\hline TI & Alegria & Tristeza & Desgosto & Surpresa & Raiva & Medo \\
\hline 101 & 93 & 4 & 2 & 0 & 1 & 1 \\
\hline 72 & 0 & 60 & 3 & 3 & 3 & 3 \\
\hline 45 & 6 & 0 & 27 & 0 & 11 & 1 \\
\hline 77 & 0 & 5 & 0 & 66 & 1 & 5 \\
\hline 36 & 1 & 1 & 9 & 0 & 25 & 0 \\
\hline 48 & 2 & 8 & 4 & 10 & 8 & 16 \\
\hline
\end{tabular}

onde, TI é o total de instâncias, cada coluna representa uma determinada emoção, e nas linhas tem-se o valor total das instâncias classificadas a cada emoção.

Através da matriz de confusão pode-se observar que a classificação da emoção alegria contendo um total de 101 instâncias, a RNA classificou 93 instâncias corretamente, porém classificou 4 com a emoção tristeza que é o oposto da emoção alvo. Para a emoção tristeza foram classificadas corretamente 60 instâncias, o restante foram classificadas como emoções similares. A emoção desgosto 27 instâncias foram classificadas corretamente, porém 11 instâncias foram classificadas com a emoção raiva.

Já para a emoção surpresa a RNA obteve bons resultados, pois foram classificados 66 instâncias corretamente, 5 como tristeza, 1 como raiva e 5 como medo. Para a emoção raiva 25 instâncias foram classificados corretamente, porém 9 foram classificadas como desgosto, 1 como alegria e 1 como medo. Por fim, para a emoção medo foram classificadas 16 instâncias corretamente, porém 10 instâncias foram classificadas como surpresa, 8 instâncias como raiva, 4 como desgosto, 8 como tristeza e 2 instâncias como alegria.

De modo geral, ao utilizar essa técnica computacional, a RNA, obteve-se uma taxa de precisão de $75.72 \%$ na classificação das emoções proposta. Tal que, 287 instâncias foram classificadas corretamente e 92 instâncias foram detectadas como falsos positivos.

\subsection{Redes Neurais com Funções de Ativação de Base Radial (RBF)}

Uma rede neural com Função de Ativação de Base Radial (RBF) consiste em um modelo neural multicamadas, capaz de aprender padrões complexos e resolver problemas não-linearmente separáveis [Scotti et al. 2010]. Parecida com a MLP, a Rede Basis Functions Networks (RBFN), ou Funções de Base Radial (RBF), são RNA's multicamadas com neurônios ocultos não-lineares). As redes RBF podem resolver problemas nãolinearmente separáveis. A principal diferença que a rede RBF tem apenas uma única camada oculta, cujos neurônios possuem função de ativação gaussiana, em vez de sigmoidal.

Foram efetuados testes utilizando essa técnica computacional com a mesma base de dados desenvolvida. Realizaram-se testes com objetivo de comparar os resultados obtidos da RNA com a rede RBF. Os dados classificados por essa rede estão dispostos na matriz de confusão e podem ser observados na Tabela 3.

Observando a matriz de confusão para essa técnica igualmente analisada para a técnica de RNA pode-se observar que para as emoções alegria, tristeza e raiva a técnica $\mathrm{RBF}$ tem resultados de classificação inferiores a técnica de RNA. Porém para as emoções desgosto, surpresa e medo, onde a RNA teve dificuldades na classificação, a técnica RBF obteve resultados mais preciso para classificação dessas emoções. 
Tabela 3. Matriz de Confusão utilizando a técnica RBF.

\begin{tabular}{|l|l|l|l|l|l|l|}
\hline TI & Alegria & Tristeza & Desgosto & Surpresa & Raiva & Medo \\
\hline 101 & 91 & 3 & 4 & 0 & 1 & 2 \\
\hline 72 & 22 & 40 & 1 & 1 & 2 & 6 \\
\hline 45 & 7 & 0 & 29 & 0 & 7 & 2 \\
\hline 77 & 0 & 2 & 0 & 73 & 0 & 2 \\
\hline 36 & 5 & 2 & 9 & 1 & 16 & 3 \\
\hline 48 & 2 & 4 & 6 & 9 & 4 & 23 \\
\hline
\end{tabular}

onde, TI é o total de instâncias, cada coluna representa uma determinada emoção, e nas linhas tem-se o valor total das instâncias classificadas a cada emoção.

Em um contexto geral, a técnica RBF obteve uma taxa de precisão de $71.76 \%$ na classificação das emoções, onde 272 instâncias foram classificadas corretamente e 107 instâncias foram detectadas como falsos positivos.

\subsection{Redes Bayesianas}

As Redes Bayesianas (RB) oferecem uma estrutura intuitiva de representar o raciocínio incerto. A vantagem de sua utilização concentra-se no sentido de permitir a representação e manipulação da incerteza com base em princípios matemáticos fundamentados. O modelo Bayesiano interpreta a probabilidade condicional, onde o grau de crença de um agente causa efeito em outro agente. Assim, $\mathrm{P}(\mathrm{A} \mid \mathrm{B})$ reflete a probabilidade de A se B ocorrer. Considerando $\mathrm{P}(\mathrm{B})$ a probabilidade a priori, probabilidade existente antes de qualquer evidência, e $\mathrm{P}(\mathrm{A})$ a probabilidade a posteriori, probabilidade após conhecer a evidência de B [Russel and Norvig 2003, Bet et al. 2004].

Essa técnica foi o terceiro método computacional escolhido para testar a base de dados. Os experimentos foram executados com os mesmos parâmetros utilizados para a técnicas de RNA e RBF. Os resultados da classificação das emoções utilizando Redes Bayesianas são mostrados na matriz de confusão da Tabela 4.

Tabela 4. Matriz de Confusão utilizando Redes Bayesianas.

\begin{tabular}{|l|l|l|l|l|l|l|}
\hline TI & Alegria & Tristeza & Desgosto & Surpresa & Raiva & Medo \\
\hline 101 & 97 & 2 & 0 & 0 & 0 & 2 \\
\hline 72 & 0 & 63 & 1 & 1 & 2 & 5 \\
\hline 45 & 2 & 0 & 36 & 0 & 7 & 0 \\
\hline 77 & 2 & 0 & 0 & 72 & 0 & 3 \\
\hline 36 & 0 & 2 & 9 & 0 & 23 & 2 \\
\hline 48 & 6 & 0 & 1 & 2 & 4 & 35 \\
\hline
\end{tabular}

onde, TI é o total de instâncias, cada coluna representa uma determinada emoção, e nas linhas tem-se o valor total das instâncias classificadas a cada emoção.

De modo geral, ao comparar os resultados da classificação com as outras duas técnicas escolhidas a Rede Bayesiana foi a técnica que obteve maior taxa de acerto, resultando em um total $86 \%$ de precisão, onde foram classificadas corretamente 326 instâncias, e apenas 53 instâncias foram classificadas como falsos positivos.

\section{Resultados Obtidos}

Neste estudo foram utilizadas três técnicas de classificação de emoções: Redes Neurais Artificiais (RNA) do tipo Multi-Layer Perceptron (MLP); a Rede Basis Functions 
Networks (RBFN) - Funções de Base Radial (RBF) - e as Redes Bayesianas (RB).

Desse modo, a classificação da emoção alegria, foi a que obteve melhor classificação com precisão maior que $90 \%$ em todas as técnicas comparadas. Em contrapartida a emoção raiva foi emoção que obteve pior taxa de acerto nas três técnicas validadas. Para as outras emoções, os resultados foram satisfatórios. Na Tabela 5 tem-se o comparativo geral do percentual de acerto mostrado nas Tabelas 2, 3 e 4 para cada uma das seis diferentes emoções. A classificação errônea das emoções comparando as Tabelas 2, 3 e 4, se deve ao fator de um mesmo músculo ser responsável por excitar mais de uma emoção, gerando assim, falsos positivos.

Tabela 5. Classificação de cada emoção comparado as três técnicas.

\begin{tabular}{|l|l||l|l||l|l||l|l|}
\hline Emoções & TI & MLP & Acerto & RBF & Acerto & RB & Acerto \\
\hline Alegria & 101 & 93 & $92,08 \%$ & 91 & $90,10 \%$ & 97 & $96,04 \%$ \\
\hline Tristeza & 72 & 60 & $83,33 \%$ & 40 & $55,56 \%$ & 63 & $87,50 \%$ \\
\hline Desgosto & 45 & 27 & $60,00 \%$ & 29 & $64,44 \%$ & 36 & $80,00 \%$ \\
\hline Surpresa & 77 & 66 & $85,71 \%$ & 73 & $94,81 \%$ & 72 & $93,51 \%$ \\
\hline Raiva & 36 & 25 & $69,44 \%$ & 16 & $44,44 \%$ & 23 & $63,89 \%$ \\
\hline Medo & 48 & 16 & $33,33 \%$ & 23 & $47,92 \%$ & 35 & $72,92 \%$ \\
\hline
\end{tabular}

onde, TI é o Total de Instâncias e o Acerto é dado em porcentagem (\%).

Em um contexto geral analisado pelas três matrizes de confusão, pode-se verificar também que para todas as emoções, exceto para as emoções raiva e surpresa, a técnica de Redes Bayesianas foi a que obteve melhor taxa de acerto na classificação das seis emoções comparada as Redes Neurais Artificias e RBF. Tais técnicas obtiveram uma precisão geral de $86 \%, 75.72 \%$ e $71.76 \%$ respectivamente.

\section{Considerações Finais}

Neste trabalho foi feito um estudo comparativo de três importantes técnicas computacionais utilizadas para classificação de emoções baseado em UA's dos músculos da face de indivíduos. Pode-se, dessa maneira, observar que essas técnicas abordadas obtiveram bons resultados para classificação das seis emoções com a mesma base de dados de [Kanade and Cohn 2005], sendo que a Rede Bayesiana obteve sucesso sobre as demais.

O objetivo do trabalho foi concluído, pois provou-se de maneira sucinta que as técnicas apresentadas conseguem captar, de forma clara, as emoções do indivíduo, recomendando em maior grau as Redes Bayesianas.

Como trabalhos futuros pretende-se validar essa mesma base de dados utilizando Cadeias de Markov. Após a validação da melhor técnica de classificação das emoções básicas sugere-se, ainda, como trabalho futuro confeccionar diferentes Objetos de Aprendizagem para que esses processos sejam incorporados à um ambiente virtual de aprendizagem e juntos, possa classificar de forma precisa as emoções do estudante. É, após detectada uma emoção que possa interferir no processo de aprendizagem o AVA ofereça um objeto de aprendizagem adequado para o estudante. Desse modo, pode-se estimular o estudante de maneira personalizada.

\section{Referências}

Azcarate, A., Hageloh, F., Sande, K. V., and Valenti, R. (2005). Automatic facial emotion recognition. Universiteit van Amsterdam. 
Bet, S., Frozza, A. A., and Arrud, A. A. C. (2004). Banco de desafios: uma aplicação de hipermídia adaptativa e redes bayesianas. XV Simpósio Brasileiro de Informática na Educação - SBIE - UFAM. http://www.br-ie.org/pub/index.php/sbie/article/view/381.

Diniz, F. A., Mendes, F. M., Junior, F. C. L., Fontes, L. M. O., Domingues, T. A. L., and Figueiredo, L. S. (2013). Um sistema de reconhecimento de expressões faciais para apoiar um ambiente virtual de aprendizagem. IX Simpósio Brasileiro de Sistemas de Informação (SBSI), pages 464 - 474. http://www.lbd.dcc.ufmg.br/colecoes/sbsi/2013/0042.pdf.

Ekman, P. and Friesen, W. (1978). Facial action coding system. Alto: Consulting Psychologist Press.

Ekman, P., Friesen, W. V., and Hager, J. C. (2002). The facial action coding system. Research Nexus eBook.

Ekman, P. and Rosenberg, E. (2005). What the Face Reveals: Basic and Applied Studies of Spontaneous Expression Using the Facial Action Coding System (FACS). Oxford University Press, New York, USA.

Fausett, L. (1994). Fundamentals of Neural Networks - Architectures, Algorithms, and Applications. Prentice-Hall, New York, USA, 1st edition.

Garcia, L. S. L. (2009). A expressão das emoções no homem e nos animais. In Traduzido por: Leon de Souza Lobo Garcia - A Origem das Espécies, publicado por Charles Darwin - 1859, pages 33-55, São Paulo, Brasil. Companhia de Bolso. http://www.letras.ufmg.br/arquivos/matte/bib/darwin.pdf.

Kanade, T. C. and Cohn, J. (2005). Au-coded facial expression database.

Lucey, P., Cohn, J. F., Kanade, T., Saragih, J., Ambadar, Z., and Matthews, I. (2010). The extended cohn-kanade dataset (ck+): A complete dataset for action unit and emotionspecified expression.

Moura, F. F., Franco, L. M., and Melo, S. L. Fernandes, M. A. (2013). Evolução das inteligências múltiplas pelo método da espiral de aprendizagem de kolb utilizando pso. XXIV Simpósio Brasileiro de Informática na Educação. http://www.brie.org/pub/index.php/sbie/article/view/1794/1555.

Oliveira, E. and Jaques, P. A. (2013). Classificação de emoções básicas através de imagens capturadas em videos de baixa resolução. Revista Brasileira de Computação Aplicada, 5(2):40-54. http://dx.doi.org/10.5335/rbca.2013.2807.

Russel, S. and Norvig, P. (2003). Artificial Intelligence: A Modern Approach. PrenticeHall, New York, USA.

Scotti, A. P., Mattos, M. C., and Simões, P. W. T. A. (2010). O método de redes neurais com função de ativação de base radial para classificação em data mining. SULCOMP, 5(1). http://periodicos.unesc.net/index.php/sulcomp/article/viewArticle/288.

Silva, C. P. E. (2012). Reconhecimento de expressões faciais utilizando redes neurais artificiais. Master's thesis, Universidade Federal da Bahia - Escola politécnica - instituto de matemática - Programa de pós-graduação em mecatrônica, Salvador, Bahia, Brasil.

Weka (2014). Weka 3: Data mining software in java. http://www.cs.waikato.ac.nz/ml/weka/. 